This document is confidential and is proprietary to the American Chemical Society and its authors. Do not copy or disclose without written permission. If you have received this item in error, notify the sender and delete all copies.

\title{
Printing of graphene nanoplatelets into highly electrically conductive three-dimensional porous macrostructures
}

\begin{tabular}{|r|l|}
\hline Journal: & Chemistry of Materials \\
\hline Manuscript ID & cm-2016-02662b.R2 \\
\hline Manuscript Type: & Article \\
\hline Date Submitted by the Author: & n/a \\
\hline Complete List of Authors: & $\begin{array}{l}\text { de la Osa, Gregorio; Institute of Ceramics and Glass (ICV-CSIC) } \\
\text { Pérez-Coll, Domingo; Consejo Superior de Investigaciones Científicas, } \\
\text { Instituto de Cerámica y Vidrio } \\
\text { Miranzo, Pilar; Instituto de Cerámica y Vidrio (C.S.I.C), Cerámica } \\
\text { Osendi, Maria Isabel; CSIC, Inst. Ceramica y Vidrio } \\
\text { Belmonte, Manuel; Institute of Ceramics and Glass (CSIC), }\end{array}$ \\
\hline
\end{tabular}

SCHOLARONE

Manuscripts 


\title{
Printing of graphene nanoplatelets into highly electrically conductive three- dimensional porous macrostructures
}

Gregorio de la Osa ${ }^{\mathrm{a}}$, Domingo Pérez-Coll ${ }^{\mathrm{b}}$, Pilar Miranzo ${ }^{\mathrm{a}}$, María Isabel Osendi ${ }^{\mathrm{a}}$, Manuel Belmonte $\mathrm{a}^{\mathrm{a}^{*}}$

${ }^{\mathrm{a}}$ Institute of Ceramics and Glass (ICV-CSIC), Campus de Cantoblanco. Kelsen 5, 28049 Madrid, Spain.

${ }^{b}$ Nanotechnology Research Division, Centre for Mechanical Technology and Automation, Department of Mechanical Engineering, University of Aveiro, 3810-193 Aveiro, Portugal.

*E-mail: mbelmonte@icv.csic.es (M. Belmonte)

Keywords: Graphene; 3D printing; robocasting; cellular materials; electrical conductivity

\begin{abstract}
The manufacturing of three dimensional (3D) graphene monoliths with remarkable electrical performance has become a challenging issue because their potential applications in the energy and electronic-based fields. Here we show the development of outstanding electrically conductive graphene patterned cellular structures combining a versatile and easily scalable filament printing method, such as Robocasting, with the use of highly crystalline graphene nanoplatelets (GNPs) as graphene source. Robust 3D pure graphene-based monoliths have been manufactured by printing pseudoplastic aqueous-based GNPs inks with high graphene contents (36.6 wt.\%) and further thermal
\end{abstract}


treatment by spark plasma sintering. Specific conductivities up to $385 \mathrm{~S} \cdot \mathrm{cm}^{-1}$ have been assessed along the longitudinal direction of the 3D structure, i.e., where the current mainly flowed along the struts, being more conductor than reported 3D synthesized graphene structures and up to two orders of magnitude higher than 3D printed graphene monoliths. The reported findings could open a straightforward pathway for creating, in a controlled way, a wide range of graphene-based hierarchical structures with an excellent electrical performance and robustness that could be employed for energy storage systems.

\section{INTRODUCTION}

Over the last few years there has been a growing interest in the manufacturing of three dimensional (3D) graphene structures because of their prospective applications, such as supercapacitors, batteries electrodes, filtration membranes, absorbers for contaminants, sensing devices, as well as for uses in catalysis, thermal management and biomedical applications. ${ }^{1-5}$ For many of these functions, low density, high specific surface area, high thermal conductivity, mechanical stability and, especially, excellent electrical conductivity, are basic characteristics to fulfil. Structured graphene assemblies are chiefly built up with graphene oxide (GO) nanosheets -owing to their hydrophilic nature- and more rarely with pristine graphene layers. Nevertheless, the employ of GO as the building block often requires a further chemical or thermal reduction step, if some of the unique properties of graphene -namely, electrical and thermal conductivitiesmust be recovered to some extension. In fact, the recovery of the transport properties is the main weakness of using GO.

Three types of methods are commonly employed to create porous structures, precisely; self-assembling, templated directed methods, and printing techniques. ${ }^{5}$ Latter 
methods possess some attractive advantages over the other two as they enable design and control of the particular geometry of the structure, besides offering the possibility of creating hierarchical structures, ${ }^{6}$ and even developing metamaterial characteristics. ${ }^{7,8}$ At present, very few works have been reported about the 3D printing of graphene monoliths, ${ }^{9-11}$ all of them using GOs as graphene source that required a further thermal reduction treatment. In short, stereolithography (SLA) of GO/polymer composites ${ }^{9}$ has been employed for printing 3D structures consisting entirely of graphene flakes after a pyrolytic process to reduce $\mathrm{GO}(\mathrm{rGO})$ and decompose the polymer, although poor mechanical stability and very low electrical conductivities were attained. Direct writing using continuous filament extrusion of GO-based inks produced highly compressible 3D lattices, ${ }^{10,11}$ but the complete GO reduction to highly crystalline graphene flakes was not achieved, thus limiting the electrical properties of the structures. In addition to these works, we should mention efforts aimed to develop 3D printed multifunctional graphene-based composite structures combining the properties of polymer ${ }^{4,12}$ or ceramic $^{13}$ matrices with those of graphene using either SLA ${ }^{12}$ or direct writing. ${ }^{4,13}$

Here, we prove the facile printing of robust 3D highly crystalline graphenebased monoliths with an outstanding electrical performance employing the Robocasting technique, a filament printing method, and commercial graphene nanoplatelets (GNPs). A sequential procedure was established for developing aqueous-based printable inks with high GNPs solid contents, also preserving the structural integrity of the printed scaffolds. The use for the first time of low defective graphene sheets allowed achieving porous patterned architectures with electrical conductivities up to two orders of magnitude higher than those reported for other 3D printed graphene-based structures, being even better conductors than crystalline graphene structures grown by chemical vapour deposition (CVD). ${ }^{14,15}$ 


\section{EXPERIMENTAL SECTION}

Commercial functionalized graphene nanoplatelets (GNPs, grade N008-P-10, Angstron Materials Inc., U.S.A., with average thickness and x-y dimensions of 50-100 $\mathrm{nm}$ and $7 \mu \mathrm{m}$, respectively) were employed as graphene source. Zeta potential $(\xi)$ measurements were carried out on zetasizer (NanoZS, Malvern Instruments Ltd, UK) for diluted inks (0.01 wt.\%) containing AR-GNPs and DNa-coated GNPs. The apparent viscosity $(\eta)$ and the shear storage $\left(G^{\prime}\right)$ and loss $\left(G^{\prime \prime}\right)$ moduli of the GNPs inks were determined with a rheometer (CVO 100 D, Bohlin Instruments, UK) equipped with a cone-and-plate geometry (diameter: $40 \mathrm{~mm}$; cone angle: $\left.4^{\circ}\right)$. For $\eta$, the shear rate $(\gamma)$ was increased from $0.0878-200 \mathrm{~s}^{-1}$. For $\mathrm{G}^{\prime}$ and $\mathrm{G}^{\prime}$ ' data, oscillation measurements were performed at a frequency of $1 \mathrm{~Hz}$ and ascending stress sweep $(\tau)$ from 0.5 to $1000 \mathrm{~Pa}$. All rheological tests were carried out at a constant temperature of $25^{\circ} \mathrm{C}$. Printable GNPs inks were developed sequentially adding to deionized water the following materials: 36 wt. $\%$ of GNPs, 8.8 wt. $\%$ of DNa (Darvan ${ }^{\circledR P N S}-N a$, Vanderbilt Minerals, LLC, USA; 57-68 wt.\% of water content), 2.3 wt.\% of PEG (PEG 8000, Fisher Scientific, Spain; $<5$ wt.\% of water content), and 2.8 wt.\% of PEI (PEI 25000, Sigma Aldrich, Spain; $<1$ wt. $\%$ of water content). After each addition, the ink was homogenized by planetary centrifugal mixing (ARE-250, Thinky Company, USA) at 2000 r.p.m. for 30-60 s. 3D cylindrical and cuboid GNPs periodic lattices were computer designed (RoboCAD 4.0, 3-D Inks LLC, USA) and reproduced at room temperature onto an alumina substrate with a custom three-axis robocasting system (A3200, 3-D Inks LLC, USA) using tips with inner diameter of $400 \mu \mathrm{m}$. Burning-out process was carried out in a conventional furnace at $475^{\circ} \mathrm{C}$ in air for $1 \mathrm{~h}$ with a heating/cooling rate of $3{ }^{\circ} \mathrm{C} \cdot \mathrm{min}^{-1}$. The as-printed structures were spark plasma sintered (SPS-510CE; Fuji Electronic Industrial Co., Ltd, Japan) at $1200{ }^{\circ} \mathrm{C}$ for $5 \mathrm{~min}$ in argon 
atmosphere $(\sim 8 \mathrm{kPa})$ using a heating rate of $125^{\circ} \mathrm{C} \cdot \mathrm{min}^{-1}$ up to $1100^{\circ} \mathrm{C}$ and $50^{\circ} \mathrm{C} \cdot \mathrm{min}^{-1}$ from 1100 to $1200{ }^{\circ} \mathrm{C}$.

Thermogravimetric-differential thermal analysis (TGA-DTA, SDT Q600, TA Instruments, USA) were carried out in air from room temperature to $1000{ }^{\circ} \mathrm{C}$ at a heating rate of $3{ }^{\circ} \mathrm{C} \cdot \mathrm{min}^{-1}$. X-ray photoelectron spectroscopy (XPS, SPECS GmbH, Germany) and confocal micro-Raman spectroscopy (Alpha300 WITec GmbH, Germany) with a laser wavelength excitation of $532 \mathrm{~nm}$ were employed to characterize the raw materials and printed scaffolds. Fracture surfaces of struts were observed with a field emission scanning electron microscope (FESEM; Hitachi S-4700, Japan).

The electrical properties of the scaffolds were analysed by a four-probe d.c. method. Two symmetrical Ag electrodes were applied over the two parallel external surfaces of the structures in order to assure equipotential conditions at each surface. Another pair of Ag electrodes was internally located over the lateral surface of the samples to separate the voltage reading from the field application at the active electrodes. The electrical connections were completed by four independent Pt wires attached, and covered with Ag ink, to the as-prepared four electrodes to assure a good electrical contact. The experimental procedure was performed by a potentiostat/galvanostat (Autolab PGSTAT302N, Switzerland) in galvanostatic mode by forcing a desired range of current to flow through the volume of the sample and read the voltage drop between the inner electrodes. The experimental current flow was ranged between 10 and $100 \mathrm{~mA}$ in steps of $10 \mathrm{~mA}$. An apparent conductivity $\left(\sigma_{\mathrm{ap}}\right)$ was related to the average resistance of the selected external volume of the sample to the electrical current flow $\left(\mathrm{R}_{\mathrm{av}}\right)$ by:

$$
\sigma_{\text {app }}=\frac{\mathrm{L}}{\mathrm{A}} \frac{1}{\mathrm{R}_{\mathrm{av}}}
$$


where $\mathrm{R}_{\mathrm{av}}$ was obtained by the slope of the current-voltage representation, $\mathrm{L}$ is the distance between the inner electrodes, and A the apparent transversal area of the scaffold structure. The electrical properties were analysed in air as a function of temperature from RT until reaching the complete degradation of the structure. Also, they were studied in heating/cooling cycles between RT and $450{ }^{\circ} \mathrm{C}$. The methodology was independently performed for longitudinal and transverse configurations represented in Figure $3 \mathrm{a}$ in order to obtain the conduction behaviour of the scaffolds in the direction of the constructed struts $\left(\mathrm{R}_{\mathrm{L}}\right)$ and also in the perpendicular direction $\left(\mathrm{R}_{\mathrm{T}}\right)$. The specific properties of conduction were determined by means of a resistor model, previously developed by some of the authors ${ }^{13}$, to obtain the true pathways for electric transport, after the elimination of the macroporosity contribution of the architectured scaffolds.

3D GNPs cuboid scaffolds of $11.8 \times 11.8 \times 9.0 \mathrm{~mm}^{3}$ were compression tested using a universal testing machine (ZwickiLine Z5.0 TS, Zwick-Roell, Germany) and a displacement rate of $0.5 \mathrm{~mm} \cdot \mathrm{min}^{-1}$ until crushing. The robocast specimens were previously ground at the top/bottom surfaces (cell-side) and at the lateral walls (frameside) to assure a homogenous distribution of the load on the whole 3D structure.

\section{RESULTS AND DISCUSSION}

The first challenged step was to produce inks with high GNPs solid contents. For that purpose, a dispersant agent like sodium polynaphthalene sulfonate (DNa), a wellknown superplasticizer used in the cement industry, was added to an aqueous graphenebased suspension. Inks with maximum GNPs contents of $\sim 34$ wt.\% were achieved by adding up to $10 \mathrm{wt} . \%$ of $\mathrm{DNa}$, but higher amounts of DNa produced almost negligible improvements in the graphene solid content. DNa also led to an important change in the zeta potential $(\zeta)$ behaviour. In this way, the isoelectric point $\left(\mathrm{pH}_{\mathrm{ie}}\right)$ of the as-received 
functionalized GNPs (AR-GNPs) occurred at $\mathrm{pH} \sim 1.6$ (Figure 1a) and tend to be negatively charged for higher $\mathrm{pH}$, reaching an approximately constant $\zeta$ value of -35 $\mathrm{mV}$ at $\mathrm{pH}>6.5$. On the other hand, it was not possible to record a $\mathrm{pH}_{\mathrm{ie}}$ value for $\mathrm{DNa}-$ coated GNPs as they exhibited a good stability within the entire $\mathrm{pH}$ range, confirming that DNa was very effective in preventing agglomeration of the GNPs by electrosteric forces that prevailed over the attractive ones.

In order to get the adequate pseudoplastic behaviour for robocasting, first, a 2.3 wt. \% of polyethylene glycol (PEG) was added to the aqueous GNPs-based ink (36 wt.\% GNPs plus 8.8 wt.\% DNa); PEG acted as viscosifying agent that produced weak gel characteristics, preventing phase separation during ink extrusion. This gel was further modified by adding a $2.8 \mathrm{wt} . \%$ of polyethylenimine (PEI), a cationic polymer able to counterbalance the negative charges of the ink, producing strong gel properties. Figure $1 \mathrm{~b}$ shows the clear shear thinning behaviour of the developed ink, decreasing the apparent viscosity $(\eta)$ in more than three orders of magnitude as the shear rate $(\dot{\gamma})$ increased within the $10^{-2}-10^{2} \mathrm{~s}^{-1}$ range. This behaviour allowed extruding the GNPsbased filaments under low pressure conditions through selected tips -inner diameter of $400 \mu \mathrm{m}-$ at $\dot{\gamma}=30-70 \mathrm{~s}^{-1}(\eta=9-19 \mathrm{~Pa} \cdot \mathrm{s})$. Besides, the filaments retained their shape once printed and the 3D skeleton did not collapse after the building-up of filaments due to both the sudden rise in $\eta\left(5 \times 10^{3} \mathrm{~Pa} \cdot \mathrm{s}\right)$ and the high shear storage modulus $\left(\mathrm{G}^{\prime}\right)$ of $\sim$ $3 \times 10^{5} \mathrm{~Pa}$ (Figure 1c), which exceeded the shear loss modulus ( $\mathrm{G}$ ') by about four times at low stress. The linear viscoelastic region of G' started to decline at a stress value of $1.5 \times 10^{2} \mathrm{~Pa}$, showing a shear yield stress $\left(\tau_{\mathrm{y}}\right)$ of $\sim 7.0 \times 10^{2} \mathrm{~Pa}$ when both moduli curves crossed over. For shear stresses higher than $\tau_{\mathrm{y}}$, G' considerably decreased. The final composition of the GNPs-based ink, considering the water content of all the 
surfactants, was the following: 55.0 wt.\% DIW, 36.6 wt.\% GNPs, 8.4 wt.\% organics (69.7, 21.0, and 9.3 in vol.\%, respectively). The $\mathrm{pH}$ value of this ink was 11.2.

a)

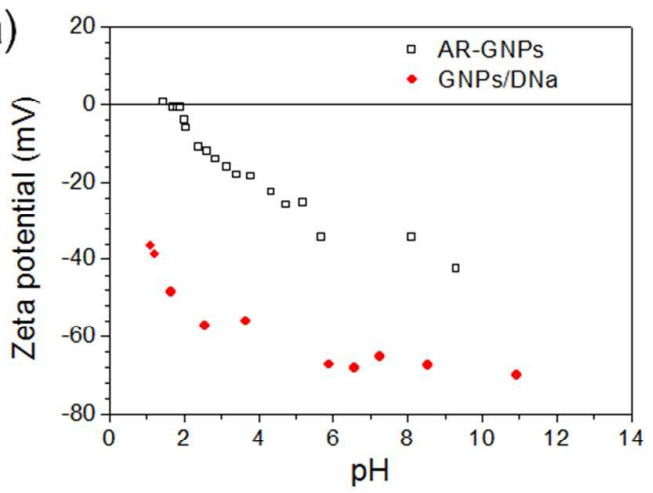

c)

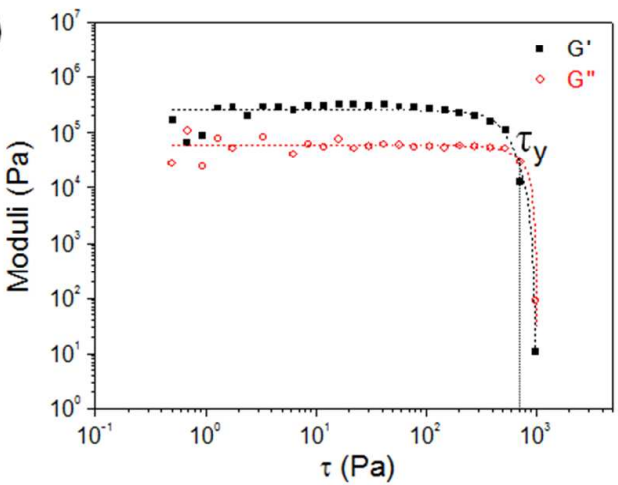

b)

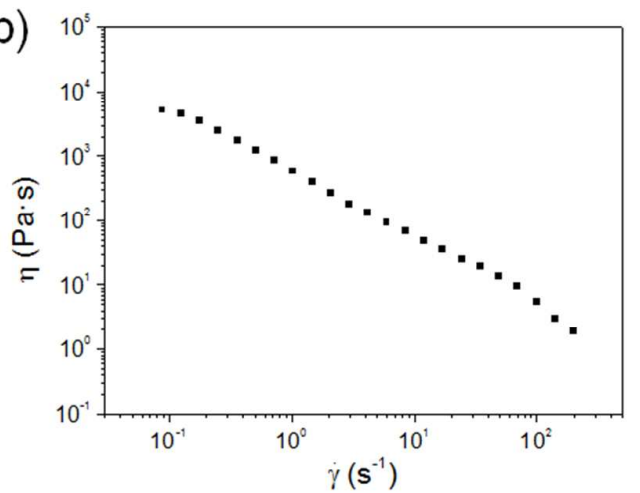

d)

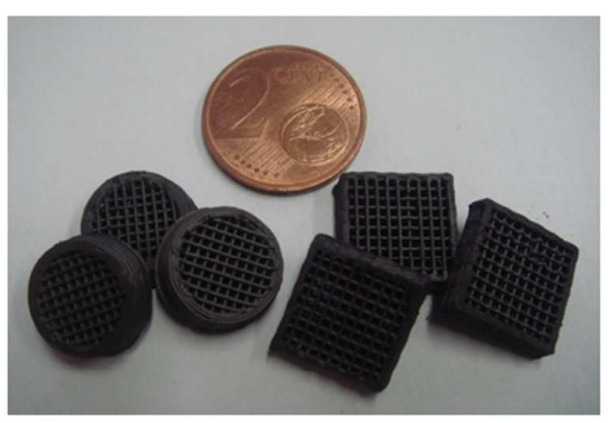

Figure 1. a) $\mathrm{pH}$ dependence of the zeta potential ( $\zeta$ ) for AR-GNPs and GNPs/DNa diluted inks, b) apparent viscosity $(\eta)$ versus shear rate $(\gamma)$, and c) shear storage $\left(\mathrm{G}^{\prime}\right)$ and loss $\left(G^{\prime \prime}\right)$ moduli versus shear stress $(\tau)$ of the GNPs-based ink. The shear yield stress $\left(\tau_{\mathrm{y}}\right)$ is pointed in c). d) Examples of 3D cylindrical and cuboid GNPs lattices.

To prove the versatility of the printing method, 3D cylindrical and cuboid GNPs periodic lattices (Figure 1d) were computer designed and reproduced with high architecture accuracy at room temperature onto an alumina substrate with a custom three-axis robocasting system. The cuboid structures of $11.8 \times 11.8 \times 9.0 \mathrm{~mm}^{3}$ were chosen for following studies. The thermogravimetric (TG) and differential thermal 
analysis (DTA) of the as-printed structures (Figure 2a) showed that DIW and DNa were eliminated in air between room temperature and $200{ }^{\circ} \mathrm{C}$; whereas PEG and PEI were burnt-out in the $200-475^{\circ} \mathrm{C}$ interval. For temperatures above $475^{\circ} \mathrm{C}$, the GNPs oxidation started and they were completely consumed at $750^{\circ} \mathrm{C}$. Accordingly, the scaffolds were thermal treated using two alternative processes: i) the low temperature treatment $\left(475^{\circ} \mathrm{C}\right.$ in air for $\left.1 \mathrm{~h}\right)$ to burn as much as possible the organics while preserving the $3 \mathrm{D}$ structure and ii) the spark plasma sintering (SPS) at $1200{ }^{\circ} \mathrm{C}$ for 5 min in argon atmosphere to provide scaffolds with a higher consistency.

a)

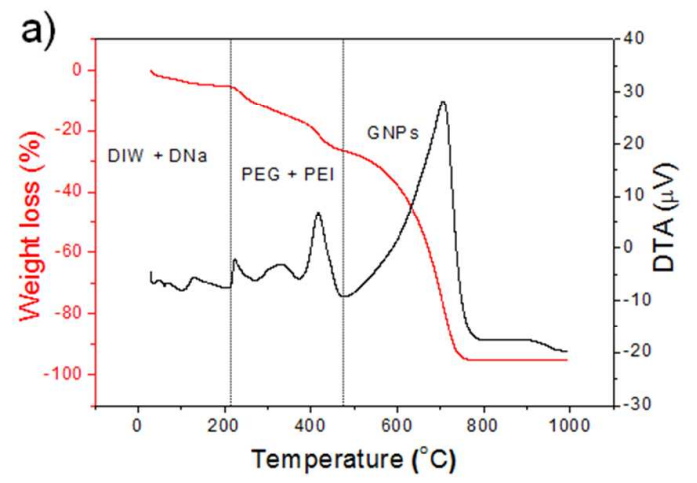

b)

\begin{tabular}{|c|c|c|c|}
\hline Element & AR-GNPs & As-printed & SPSed \\
\hline $\mathrm{C}$ & 96.67 & 89.50 & 96.10 \\
\hline $\mathrm{O}$ & 2.67 & 7.08 & 2.39 \\
\hline $\mathrm{N}$ & 0.13 & 1.95 & 0.05 \\
\hline $\mathrm{Na}$ & 0.12 & 0.59 & 0.51 \\
\hline $\mathrm{S}$ & 0.16 & 0.59 & 0.62 \\
\hline $\mathrm{Si}$ & 0.25 & 0.29 & 0.33 \\
\hline
\end{tabular}

c)

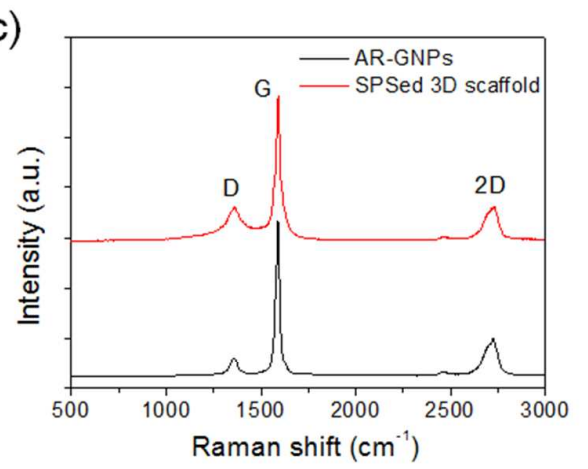

Figure 2. a) Thermogravimetric (weight loss) and differential thermal analysis (DTA) of the as-printed GNPs scaffolds. The temperature regions where the different components are burnt-out are indicated. b) Elemental atomic percentage from XPS spectrum for ARGNPs powders and as-printed and SPSed 3D GNPs scaffolds. c) Raman spectra of the AR-GNPs powders and SPSed 3D GNPs structure. 
Whereas the burnt-out structures behaved very fragile and easily collapsed while handling, the SPSed 3D scaffolds were readily manipulated without any signs of damage or deformation. The low temperature process removed most of the organics leaving feeble bonds between the nanoplatelets that maintained the 3D structure; while the SPS treatment provided strength to the structures despite most of the organics were also eliminated. In fact, the weight loss after the SPS process was above $60 \%$ (the water plus organics weight content of the ink was $\sim 63 \%$ ). The reason for that mechanical stability of the 3D printed structures after the SPS process must be related to GNP-GNP joints locally grown by surface and vapour phase matter transfer at high temperature assisted by the electric field applied during SPS. ${ }^{16}$ Based on the above results, burnt-out specimens were discarded henceforth focusing the attention on the SPSed 3D scaffolds.

The apparent density of the SPSed cuboid lattices, estimated from the scaffold dimensions and weight, was $0.34 \mathrm{~g} \cdot \mathrm{cm}^{-3}$, with a GNPs strut diameter of around $400 \mu \mathrm{m}$ and a distance between two adjacent struts of $\sim 700 \mu \mathrm{m}$. Assuming a density of 2.2 $\mathrm{g} \cdot \mathrm{cm}^{-3}$ for GNPs, the total porosity of the 3D scaffolds was estimated as $84.5 \%$, which corresponded to the sum of the macro-voids due to the patterned design $(68.3 \%)$ and the micro-porosity associated to the GNPs struts (16.2\%).

X-ray photoelectron (XPS) and micro-Raman spectroscopies were employed to elucidate the quality of GNPs after the SPS treatment. XPS analyses (Table in Figure 2b and Figure S1, Supporting Information) evidenced that the amount of oxygen in the asprinted GNPs monoliths (7.08 at.\%) considerably increased as compared to the ARGNPs $(2.67$ at.\%), which would be linked to the addition of surfactants to the graphenebased ink, especially DNa and PEG. In fact, the O1s core-level spectrum for the asprinted GNPs monoliths (Figure S1b) exhibited more intense peaks at $531.7 \mathrm{eV}$ and 
$533.4 \mathrm{eV}$, assigned to $\mathrm{C}=\mathrm{O}$ and $\mathrm{C}-\mathrm{O}$ bonds, respectively, ${ }^{17}$ than those recorded for ARGNPs. The as-printed structures also contained a larger amount of nitrogen (coming from PEI), sodium (DNa), and sulphur (DNa) (Figure 2b). Interestingly, after the SPS process, the 3D structures almost entirely recovered the purity of the AR-GNPs powders, losing most of the impurities and only remaining a low amount of sodium and sulphur residues (total content of 1.13 at. $\%$ vs 0.28 at. $\%$ for AR-GNPs). The presence of sulphur could affect the electrical and electrochemical properties of the samples, as this element was suggested to be an effective n-type dopant for graphene, creating charge sites that enhance the electrical properties. ${ }^{18,19}$ In this context, enhanced electrocatalytic activity for oxygen reduction was reported for sulphur doped graphene, which has a positive impact in the energy conversion efficiency of the cathodic reaction in fuel cells. ${ }^{20}$ The improvement of the oxygen reduction reaction activity has been attributed to the structural distortion and change of charge density induced after sulphur doping. ${ }^{21}$ The benefit of sulphur doping in graphene has also been reported for other electrochemical devices such as lithium-ion batteries and supercapacitors. ${ }^{21}$

Raman spectra for AR-GNPs and SPSed 3D GNPs scaffold (Figure 2c) clearly showed the characteristic peaks of graphene-based species, i.e., D-, G-, and 2D-bands. When comparing the intensity ratio between $\mathrm{D}$ - and G-bands $\left(\mathrm{I}_{\mathrm{D}} / \mathrm{I}_{\mathrm{G}}\right)$, which gives an idea of the crystallinity or defective degree of the graphene-based structure, between the SPSed 3D GNPs scaffold and the pristine AR-GNPs, almost identical Raman patterns with very low and quite similar $\mathrm{I}_{\mathrm{D}} / \mathrm{I}_{\mathrm{G}}$ values $(0.31 \mathrm{vs} 0.29$, respectively) were obtained. This fact proves that GNPs are highly crystalline and remained undamaged after the SPS process.

As it was previously reported by Jakus et al. ${ }^{4}$ and some of the present authors ${ }^{13}$ for 3D printed graphene/polymer and graphene/ceramic composites, respectively, the 
graphene flakes appeared with the ab plane parallel aligned to the strut axis (Figure 3) due to the shear forces occurring at the nozzle tip during the printing process. The GNPs alignment is clearly observed at both the strut surface (Figure $3 \mathrm{~b}$ ) and cross-section (Figure 3c and 3,d). Furthermore, the aligned GNPs seem to be randomly distributed in the radial direction in the core (Figure 3c), whereas they show a certain orientation, parallel to the rod wall, in the external shell (Figure 3d). This GNPs alignment would probably play an important role in the transport properties, especially in the electrical conductivity as some of the authors showed for GNPs/SiC composite structures. ${ }^{13}$ Indeed, this alignment effect can be seen in Figure 4, where the electrical performance of the as-printed and SPSed 3D GNPs monoliths is highlighted.
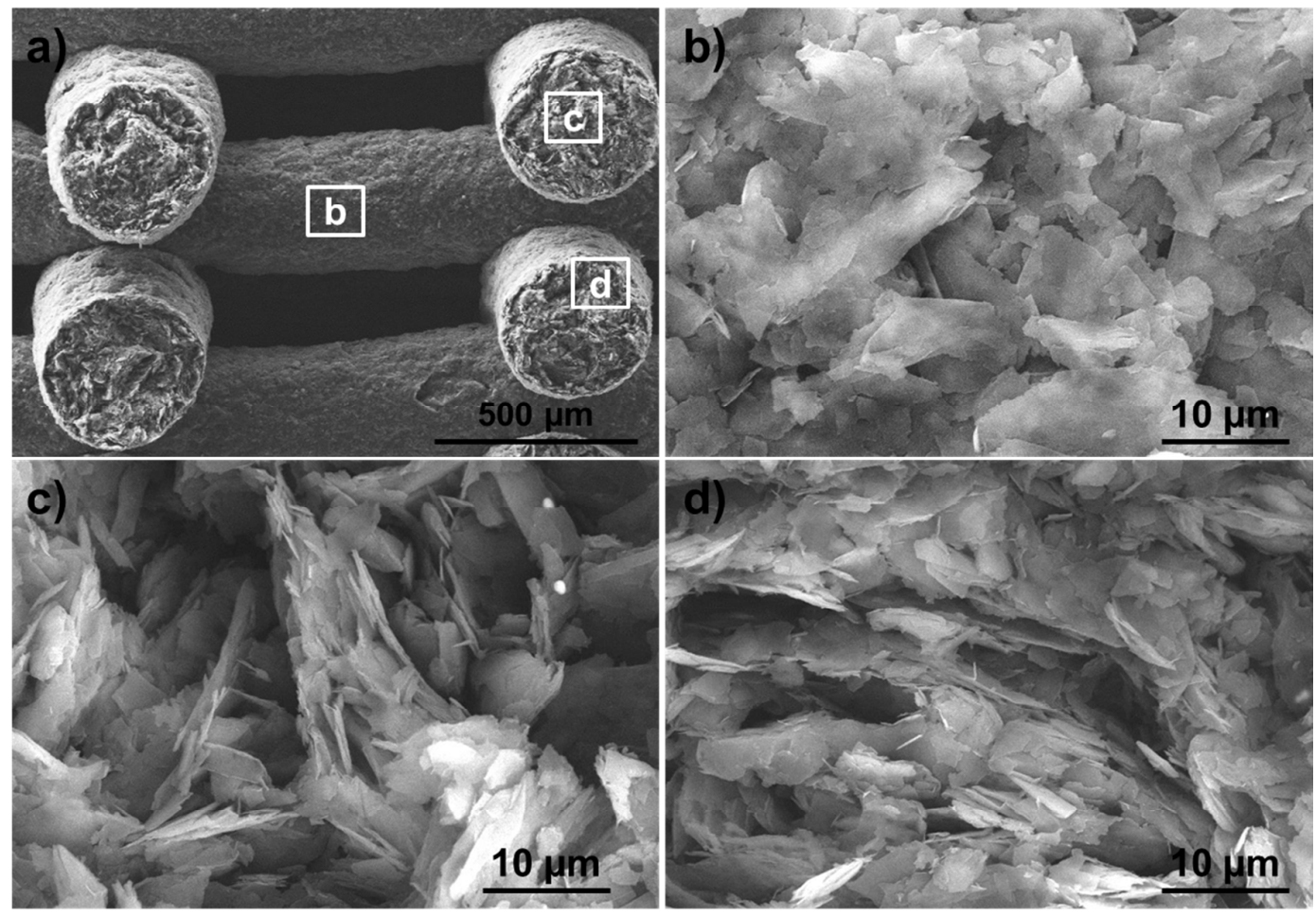

Figure 3. a-d) FESEM micrographs of the fracture surface of SPSed 3D GNPs structure: outermost surface of the GNPs struts (b), and images of the strut cross-section at the core (c) and external shell (d). 
The apparent electrical conductivity $\left(\sigma_{\mathrm{ap}}\right)$ was measured in air from room temperature (RT) up to $450{ }^{\circ} \mathrm{C}$ in two scaffold directions according to its architecture (Figure 4a): longitudinal $(L)$ and transverse $(T)$, where the current mainly flowed along the struts or through the struts of successive layers, respectively. The as-printed GNPs structures exhibited moderate $\sigma_{\text {ap }}$ values at RT (Figure $4 \mathrm{~b}$ ), $L$ direction being $\sim 67 \%$ more conductor $\left(1.0 \mathrm{~S} \cdot \mathrm{cm}^{-1}\right)$ than $T$ one $\left(0.6 \mathrm{~S} \cdot \mathrm{cm}^{-1}\right)$, which suggests that the electrical transport is enhanced when current flows parallel to the rod axis and, hence, to the ab graphene plane of the nanoplatelets. $\sigma_{\text {ap }}$ considerably increased with the temperature (Figure $4 \mathrm{~b})$, augmenting $\sim 28$ times for $L\left(28.0 \mathrm{~S} \cdot \mathrm{cm}^{-1}\right)$ and $\sim 20$ times for $T\left(12.0 \mathrm{~S} \cdot \mathrm{cm}^{-}\right.$ ${ }^{1}$ ) directions at $450^{\circ} \mathrm{C}$. This abrupt improvement in conductivity is mainly linked to the progressive burning-out process of the non-conductive organic surfactants used for the ink formulation (see TG/DTA in Figure 2a). For higher temperatures, $\sigma_{\text {ap }}$ sharply decreased (not shown in the plots) due to the degradation by oxidation of the GNPs. Interestingly, the SPSed 3D graphene-based monoliths showed an outstanding electrical performance, with RT $\sigma_{\mathrm{ap}}$ values of $71.1 \mathrm{~S} \cdot \mathrm{cm}^{-1}$ and $46.0 \mathrm{~S} \cdot \mathrm{cm}^{-1}$ for $L$ and $T$ directions, respectively, that represent the highest values reported hitherto for $3 \mathrm{D}$ graphene structures developed with any solution processing technique or chemical vapour deposition process $^{5}$ (see a summary in Figure 4c). Actually, the current GNPs monoliths present an electrical conductivity about 1-2 orders of magnitude larger than the highest conductor $3 \mathrm{D}$ printed structures based on $\mathrm{rGO},{ }^{10}$ which could be mainly explained by the largest densification degree of GNPs monoliths jointly with the greatest crystallinity of GNPs as compared to the most defective rGOs, as their Raman pattern evidenced. ${ }^{10}$ Moreover, the SPSed 3D GNPs monoliths are also better conductors ( 4-7 times) than 3D crystalline graphene structures grown by CVD on nickel foams employed as templates. ${ }^{14,15}$ When the testing temperature increased up to $450{ }^{\circ} \mathrm{C}, \sigma_{\text {ap }}$ of SPSed 3D 
GNPs scaffolds augmented $\sim 40-47 \%\left(98.6 \mathrm{~S} \cdot \mathrm{cm}^{-1}\right.$ and $67.9 \mathrm{~S} \cdot \mathrm{cm}^{-1}$ for $L$ and $T$ directions, respectively). The increase on $\sigma_{\mathrm{ap}}$ must be related to changes in the electron mobility with the temperature. In fact, considering that the conductivity of n-layer graphene have two carrier transport channels (surface and interlayer), Fang et al. established $^{22}$ that the electrical conductivity of multilayer graphene would increase with temperature due to the motion of electrons in the interlayers (the surface contribution is almost negligible), being more noticeable as the number of graphene layers augments.

a)

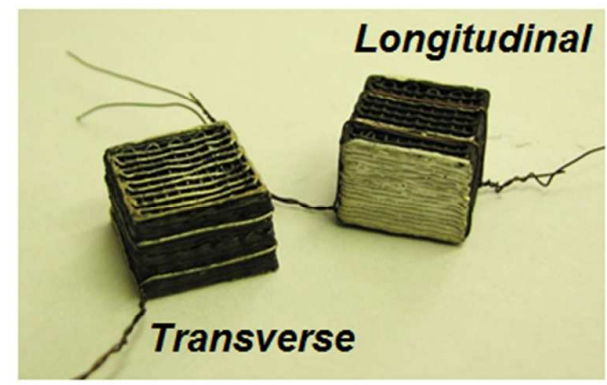

c)

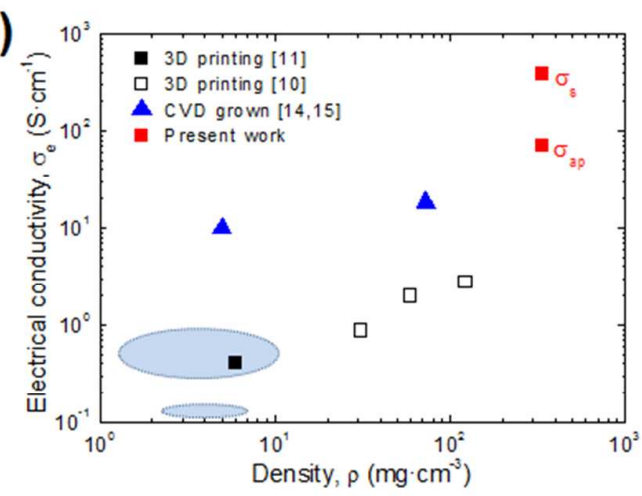

b)

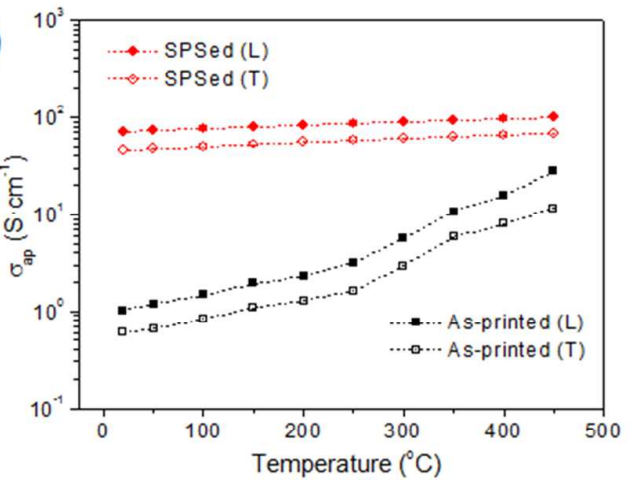

d)

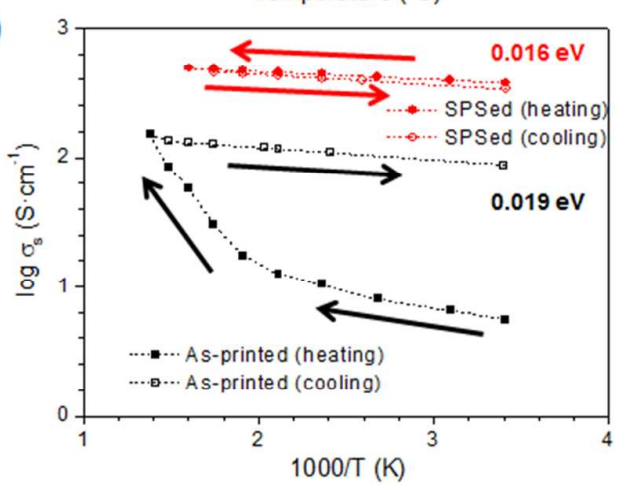

Figure 4. a) Image showing the two different arrays tested (longitudinal and transverse) to determine the electrical conductivity. b) Apparent electrical conductivity $\left(\sigma_{\mathrm{ap}}\right)$ versus temperature for the as-printed and SPSed GNPs monoliths tested in longitudinal (filled symbols) and transverse (empty symbols) arrays. c) Comparison of reported electrical conductivity $\left(\sigma_{\mathrm{e}}\right)$ values in the longitudinal direction at room temperature of 3D GNPs structures as a function of the mass density obtained by 3D printing (square symbols) including the present data (SPSed scafffolds), CVD grown (triangle symbols), and 
solution based templating techniques (blue-coloured area). d) Specific electrical conductivity $\left(\sigma_{\mathrm{s}}\right)$ versus temperature during the heating (full symbols)-cooling (empty symbols) cycle for the as-printed and SPSed GNPs monoliths tested in the longitudinal direction.

The apparent electrical conductivities shown above were calculated from the experimental conductances of the scaffolds and their external apparent dimensions. The resistor model, developed by some of the present authors for predicting the apparent conductivity of $3 \mathrm{D} \mathrm{SiC/GNPs}$ porous structures, ${ }^{13}$ stated that the longitudinal $\sigma_{\mathrm{ap}}$ directly depended on the ratio between the diameter and the separation of the struts and the specific electrical conductivity $\left(\sigma_{\mathrm{s}}\right)$ of the individual struts. Applying this model to the current 3D GNPs monoliths we calculated $\sigma_{\mathrm{s}}$-a more realistic magnitude- for the asprinted and SPSed 3D scaffolds (Figure 4d), which are both about 5.5 times higher than $\sigma_{\text {ap }}$ due to the use of the true volume of conduction. In this way, $\sigma_{\mathrm{s}}$ values of 5.6 and 149.5 $\mathrm{S} \cdot \mathrm{cm}^{-1}$ were assessed for the as-printed structures at RT and $450^{\circ} \mathrm{C}$, respectively; whereas the SPSed 3D monoliths reached $384.6 \mathrm{~S} \cdot \mathrm{cm}^{-1}$ at RT and $533.5 \mathrm{~S} \cdot \mathrm{cm}^{-1}$ at 450 ${ }^{\circ} \mathrm{C}$. The specific conductivity determined from the resistor model is about four orders of magnitude larger than the value of $3 \mathrm{D}$ printed rGO filament pile at $\mathrm{RT},{ }^{11}$ which is a simple shape where no effects related to contact resistances between struts of orthogonal layers are expected, as it happens in the present 3D cellular architectures.

Figure $4 \mathrm{~d}$ collects $\log \sigma_{\mathrm{s}}$ data for the complete heating-cooling cycle. It is interesting to note that the as-printed scaffolds showed a hysteresis cycle and $\sigma_{\mathrm{s}}$ at RT after the cooling step is higher $\left(90.0 \mathrm{~S} \cdot \mathrm{cm}^{-1}\right)$ than the value attained before the heating process $\left(5.6 \mathrm{~S} \cdot \mathrm{cm}^{-1}\right)$. During the first step of this process $\left(<200^{\circ} \mathrm{C}\right)$ a slight enhancement of the conductivity was observed, abruptly increasing in the $200-450{ }^{\circ} \mathrm{C}$ 
range due to the largest organic decomposition degree (Figure 2a). During the cooling ramp, and once all the organics were removed, $\sigma_{\mathrm{s}}$ slightly decreased until RT. In the case of SPSed 3D GNPs monoliths, the electrical data for both ramps overlapped because their lack of volatile matter. According to the observed lineal dependence of $\sigma_{\mathrm{s}}$ observed with temperature (Figure $4 \mathrm{~d}$ ) for both 3D structures when organics were completely removed, i.e. as-printed structure on the cooling stage and SPSed 3D structure on the whole heating/cooling process, the electrical behaviour fitted to the nearest-neighbour hopping mechanism $(\mathrm{NNH})$ in which a thermal improvement of conductivity is expected: ${ }^{23}$

$$
\sigma_{S}=\sigma_{0} \exp \left(-\frac{E_{a}}{k_{B} T}\right)
$$

where $\mathrm{k}_{\mathrm{B}}$ is the Boltmann constant, $\sigma_{0}$ the pre-exponential factor, and $\mathrm{E}_{\mathrm{a}}$ is the activation energy associated to the electronic hopping to the nearest-neighbour state, which shows values during the cooling process of $\sim 0.019$ and $0.016 \mathrm{eV}$ for the asprinted and SPSed 3D monoliths, respectively. The NNH mechanism was also described for graphene- and carbon nanotube-based systems ${ }^{23,24}$ when a similar temperature range was analysed.

In addition to an outstanding electrical performance, the 3D printed GNPs structures also exhibited robustness and mechanical stability (Figure 5). Figure 5a collects representative examples of the stress-strain curves for as-printed and SPSed 3D GNPs scaffolds compression tested on both the cell-side (patterned sides facing compression platens) and frame-side (compression on opposite sides of the frame) surfaces. All the tested structures showed the typical behaviour of cellular materials, with an initial linear elastic region linked to the bending of the cells, followed by the densification of cells where the maximum compressive strength (crushing) was reached 
and, finally, the progressive fracture of the 3D structure by collapsing the individual GNPs cells, decreasing the strength while the strain augmented. This gradual collapse of the cells, evidenced by the stress peaks registered during the tests (Figure 5a) that were also audible, avoided the catastrophic failure of the scaffolds. Figure $5 \mathrm{c}$ and $5 \mathrm{~d}$ depict the sequence of images during compression of the SPSed 3D monoliths for both testing configurations on the cell-side (Figure 5c) and frame-side (Figure 5d) surfaces. In the former case, the individual GNPs cells crushed and some visible cracks developed, running along the load direction (see arrows pointed in Figure 5c), leading to the partial collapse of the structure. However, when tested the frame-side surface, the load was mainly supported by the frame that progressively separated from the cellular structure, which mostly maintained its integrity (Figure 5d).
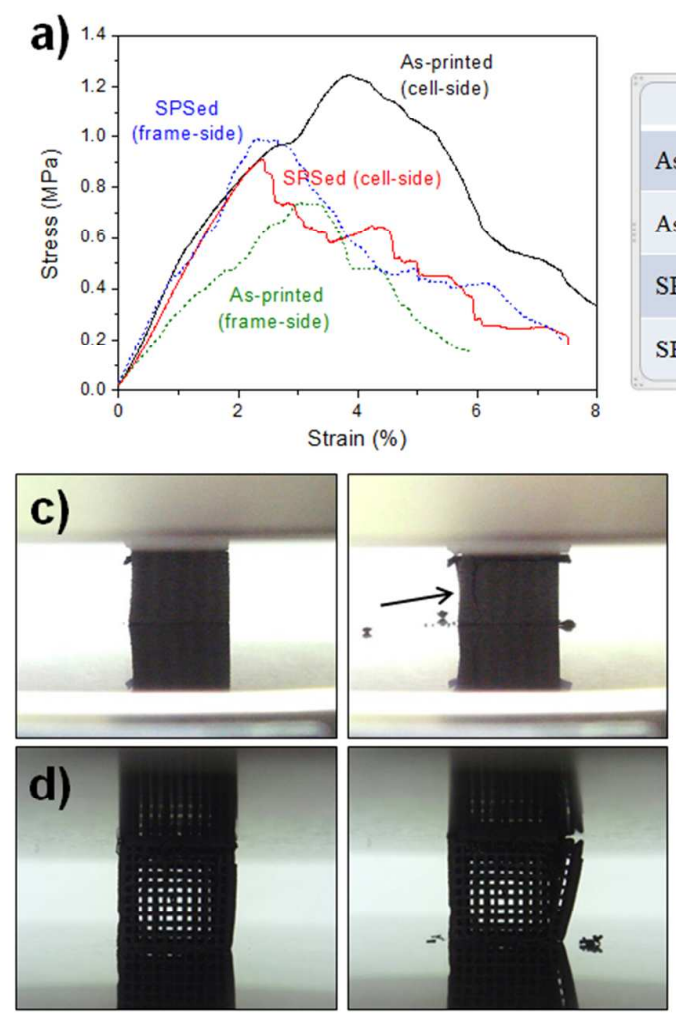

\section{b)}

\begin{tabular}{|l|c|c|c|}
\hline \multicolumn{1}{|c|}{ 3D structure } & E (MPa) & $\boldsymbol{\sigma}(\mathbf{M P a})$ & $\varepsilon(\%)$ \\
\hline As-printed (cell-side) & $0.58 \pm 0.04$ & $1.13 \pm 0.17$ & $3.48 \pm 0.30$ \\
\hline As-printed (frame-side) & $0.30 \pm 0.03$ & $0.81 \pm 0.11$ & $3.02 \pm 0.56$ \\
\hline SPSed (cell-side) & $0.35 \pm 0.07$ & $0.81 \pm 0.15$ & $3.50 \pm 1.19$ \\
\hline SPSed (frame-side) & $0.41 \pm 0.09$ & $1.01 \pm 0.03$ & $3.21 \pm 1.26$ \\
\hline
\end{tabular}

Figure 5. a) Representative stress-strain curves for as-printed and SPSed scaffolds compressive tested on the cell-side and frame-side surfaces, b) table summarizing the 
average elastic modulus $(E)$, crushing strength $(\sigma)$ and the related strain at the maximum $\sigma(\varepsilon$, in $\%)$ for the different 3D structures, $c)$ and d) sequential images taken during the compressive tests on cell-side (c) and frame-side (d) surfaces of the SPSed scaffolds. The black arrows in c) point the cracks developed during the collapse of the $3 \mathrm{D}$ structure.

The as-printed scaffolds tested on the cell-side surface exhibited the highest stiffness $(E=0.58 \mathrm{MPa})$ and crushing strength $(\sigma=1.13 \mathrm{MPa})$ of all set of materials (Table in Figure 5b). After the SPS process, E and $\sigma$ of the GNPs monoliths decreased in about $40 \%(0.35 \mathrm{MPa})$ and $28 \%(0.81 \mathrm{MPa})$, respectively, the structures still being stiff and robust. The reduction of these parameters would be associated to the removal of polymer surfactants used for the ink formulations that helped supporting the graphene network, ${ }^{11}$ as well as to the decrease in the density of the struts. ${ }^{25}$ Previous works on lighter $3 \mathrm{D}$ printed structures based on $\mathrm{rGO}$ inks ${ }^{10,11}$ reported a wide range of $\mathrm{E}$ values varying from $0.13 \mathrm{MPa}$ for filament pile $\left(\rho=6 \mathrm{mg} \cdot \mathrm{cm}^{-3}\right)^{11}$ to $30 \mathrm{MPa}$ for aerogel microlattices $\left(\rho=55 \mathrm{mg} \cdot \mathrm{cm}^{-3}\right) .{ }^{10}$ Considering that the present GNPs monoliths are much denser $\left(340 \mathrm{mg} \cdot \mathrm{cm}^{-3}\right)$, higher E values should be expected. The easy slip upon loading of the graphene flakes would lead to a decrease on the elastic modulus and, hence, to a larger flexibility. ${ }^{4}$ This flakes slip would be promoted in the present case by both the high crystallinity of the GNPs that would reduce the mechanical interlock between the flakes, in contrast to defective graphene-based structures such as rGO, and the favourable GNPs alignment to the strut axis (Figure 3). SPSed 3D GNPs monoliths tested on the frame-side surface exhibited a $\sim 20 \%$ larger stiffness $(E=0.41 \mathrm{MPa})$ and robustness $(\sigma=1.01 \mathrm{MPa})$ than for the cell-side surface (Figure $4 \mathrm{~b})$, which could be associated to a reduction in the slipping motion of the graphene flakes considering that 
$\sim 50 \%$ of the total number of struts are now tested in the parallel direction to the GNPs alignment. The SPSed 3D GNPs monoliths tested on the cell-side surface also evidenced quite remarkable robustness, with crushing strength values $(0.81 \mathrm{MPa})$ much higher than for other pure graphene-based structures ${ }^{26,27}$ and with a similar strength than $\mathrm{SiO}_{2}$ aerogels of the same density. ${ }^{28}$

\section{CONCLUSIONS}

We have additive manufactured robust and lightweight 3D pure graphene-based cellular monoliths with an outstanding electrical conductivity from printable aqueousbased GNPs inks with high graphene contents. The use of SPS allowed removing the organics employed for the ink formulation, maintaining at the same time the integrity of the $3 \mathrm{D}$ cellular structures and the high crystallinity and potential properties of graphene. The GNPs scaffolds exhibited the largest electrical conductivity reported for 3D graphene structures hitherto, showing an anisotropic electrical behaviour within the scaffold architecture that could be useful for promising applications linked to electrical management where specific directional current flows are required. The use of both high quality graphene sheets, as graphene source, and a versatile and easy scalable printing method, such as the Robocasting, offers a unique combination to manufacture a wide range of hierarchical structures with an excellent and tailored electrical performance for, among others, supercapacitors, battery electrodes or electrochemical devices.

\section{ACKNOWLEDGEMENTS}

This work was supported by the Spanish Government (MAT2012-3294 and MAT201567437-R projects) and CSIC (PIE 201360E063 project). D. Pérez-Coll also acknowledges the financial support by FCT-BPD grant (SFRH/BPD/112282/2015). We 
thank R. Moreno from ICV-CSIC and R. Cruz-Silva from Shinshu University (Japan) for their help in the zeta potential measurements and XPS interpretation, respectively.

\section{SUPPORTING INFORMATION}

XPS deconvoluted spectra of C1s (a) and O1s (b) core levels for AR-GNPs and asprinted and SPSed 3D GNPs scaffolds. The XPS analyses evidenced the presence in all materials of $\mathrm{sp}^{2}$ - and $\mathrm{sp}^{3}$-hybridized carbon (284.5 and $\left.285.4 \mathrm{eV}\right), \mathrm{C}-\mathrm{O}(286.5 \mathrm{eV})$ and O-C-O $(287.7 \mathrm{eV})$ groups. Besides, the O1s core-level spectra mainly showed peaks at $531.7 \mathrm{eV}(\mathrm{C}=\mathrm{O}), 533.4 \mathrm{eV}(\mathrm{C}-\mathrm{O})$. Therefore, XPS data confirmed the functionalization of the pristine nanoplatelets. The addition of surfactants to produce the graphene-based ink led to more intense $\mathrm{C}-\mathrm{O}$ and $\mathrm{C}=\mathrm{O}$ bands, which considerably decreased in intensity after the SPS process.

\section{REFERENCES}

(1) Zhang, L.; Zhang, F.; Yang, X.; Long, G.; Wu, Y.; Zhang, T.; Leng, K.; Huang, Y.; Ma, Y.; Yu, A.; Chen, Y. Porous 3D graphene-based bulk materials with exceptional high surface area and excellent conductivity for supercapacitors. Sci. Rep. 2013, 3, 1408.

(2) Wu, Y.; Yi, N.; Huang, L.; Zhang, T.; Fang, S.; Chang, H.; Li, N.; Oh, J.; Lee, J. A.; Kozlov, M.; Chipara, A. C.; Terrones, H.; Xiao, P.; Long, G.; Huang, Y.; Zhang, F.; Zhang, L.; Lepró, X.; Haines, C.; Lima, M. D. et al. Three-dimensionally bonded spongy graphene material with super compressive elasticity and near-zero Poisson's ratio. Nat. Comm. 2015, 6, 6141. 
(3) Ma, Y.; Chen, Y. Three-dimensional graphene networks: synthesis, properties and applications. Nat. Sci. Rev. 2015, 2, 40-53.

(4) Jakus, A. E.; Secor, E. B.; Rutz, A. L.; Jordan, S. W.; Hersam, M. C.; Shah, R. N. Three-dimensional printing of high-content graphene scaffolds for electronic and biomedical applications. ACS Nano 2015, 9, 4636-4648.

(5) Sherrell, P. C.; Mattevi, C. Mesoscale design of multifunctional 3D graphene networks. Mater. Today, DOI:10.1016/j.mattod.2015.12.004.

(6) Raney, J. R.; Lewis, J. A. Printing mesoscale architectures. MRS Bull. 2015, 40, 943-950.

(7) Kruisová, A.; Seiner, H.; Sedlák, P.; Landa, M.; Román-Manso, B.; Miranzo, P.; Belmonte M. Acoustic metamaterial behavior of three-dimensional periodic architectures assembled by robocasting. Appl. Phys. Lett. 2014, 105, 211904.

(8) Rafsanjani, A.; Akbarzadeh, A.; Pasini, D. Snapping mechanical metamaterials under tension. Adv. Mater. 2015, 27, 5931-5935.

(9) Korhonen, H.; Sinh, L. H.; Luong, N. D.; Lehtinen, P.; Verho, T.; Partanen, J.; Seppälä J. Fabrication of graphene-based 3D structures by stereolithography. Phys. Status Solidi A 2016, 213, 982-985.

(10) Zhu, C.; Han, T. Y.-J.; Duoss, E. B.; Golobic, A. M.; Kuntz, J. D.; Spadaccini, C. M.; Worsley, M. A. Highly compressible 3D periodic graphene aerogel microlattices. Nat. Comm. 2015, 6, 6962.

(11) García-Tuñon, E.; Barg, S.; Franco, J.; Bell, R.; Eslava, S.; D'Elia, E.; Maher, R. C.; Guitian, F.; Saiz, E. Printing in three dimensions with graphene. Adv. Mater. 2015, $27,1688-1693$. 
(12) Lin, D.; Jin, S.; Zhang, F.; Wang, C.; Wang, Y.; Zhou, C.; Cheng, G. J. 3D

stereolithography printing of graphene oxide reinforced complex architectures.

Nanotechnol. 2015, 26, 434003.

(13) Román-Manso, B.; Figueiredo, F. M.; Achiaga, B.; Barea, R.; Pérez-Coll, D.;

Morelos-Gómez, A.; Terrones, M.; Osendi, M. I.; Belmonte, M.; Miranzo, P.

Electrically functional 3D-architectured graphene/SiC composites. Carbon 2016, 100, 318-328.

(14) Chen, Z.; Ren, W.; Gao, L.; Liu, B.; Pei, S.; Cheng, H.-M. Three-dimensional flexible and conductive interconnected graphene networks grown by chemical vapour deposition. Nat. Mater. 2011, 10, 424-428.

(15) Min, B. H.; Kim, D. W.; Kim, K. H.; Choi, H. O.; Jang, S. W.; Jung, H.-T. Bulk scale growth of CVD graphene on Ni nanowire foams for a highly dense and elastic 3D conducting electrode. Carbon 2014, 80, 446-452.

(16) Holland, T.B.; Anselmi-Tamburini, H.; Quacha, D. V.; Tran, T. B.; Mukherjee, A. K. Local field strengths during early stage field assisted sintering (FAST) of dielectric materials. J. Eur. Ceram. Soc. 2012, 32, 3659-3666.

(17) Drewniak, S.; Muzyka, R.; Stolarczyk, A.; Pustelny, T.; Kotyczka-Morańska, M.; Setkiewicz, M. Studies of reduced graphene oxide and graphite oxide in the aspect of their possible application in gas sensors. Sensors 2016, 16, 103.

(18) Kotal, M.; Kim, J.; Kim, K. J.; Oh, I.-K. Sulfur and nitrogen co-doped graphene electrodes for high-performance ionic artificial muscles. Adv. Mater. 2016, 28, 16101615.

(19) Choi, H.; Jo, H.-H.; Hwang, S.; Je, M. Synthesis of sulfur-doped graphene by using near-infrared chemical-vapor deposition. J. Korean Phys. Soc. 2016, 68, L1257-L1261. 
(20) Yang, Z.; Yao, Z.; Li, G.; Fang, G.; Nie, H.; Liu, Z.; Zhou, X.; Chen, X.; Huang, S. Sulfur-doped graphene as an efficient metal-free cathode catalyst for oxygen reduction. ACS Nano 2012, 6, 205-211.

(21) Paraknowitsch, J. P.; Thomas, A. Doping carbons beyond nitrogen: an overview of advanced heteroatom doped carbons with boron, sulphur and phosphorus for energy applications. Energy Environ. Sci. 2013, 6, 2839-2855.

(22) Fang, X.-Y.; Yu, X.-X.; Zheng, H.-M.: Jin, H.-B.; Wang, L.; Cao, M.-S.

Temperature-and thickness-dependent electrical conductivity of few-layer graphene and graphene nanosheets. Phys. Lett. A 2015, 379, 2245-2251.

(23) Martin, I.; Blanter, Y. M. Transport in disordered graphene nanoribbons. Phys. Rev. B 2009, 79, 235132.

(24) Davydov, D. N.; Li, J.; Shelimov, K. B.; Haslett, T. L.; Moskovits, M.; Statt, B. W. Resistance and tunneling spectra of aligned multiwalled carbon nanotube arrays. $J$. Appl. Phys. 2000, 88, 7205.

(25) Gibson, L. J.; Ashby, M. F. In Cellular Solids Structure and Properties ( $2^{\text {nd }}$ ed.); Cambridge Univ. Press, UK, 1999.

(26) Barg, S.; Perez, F. M.; Ni, N.; Pereira, P. V.; Maher, R. C.; Garcia-Tuñon, E.; Eslava, S.; Agnoli, S.; Mattevi, C.; Saiz, E. Mesoscale assembly of chemically modified graphene into complex cellular networks. Nat. Comm. 2014, 5, 4328.

(27) Ferraro, C.; Garcia-Tuñon, E.; Rocha, V. G.; Barg, S.; Fariñas, M. D.; AlvarezArenas, T. E. G.; Sernicola, G.; Giuliani, F.; Saiz, E. Light and strong SiC networks. Adv. Func. Mater. 2016, 26, 1636-1645. 
(28) Woignier, T.; Reynes, J.; Alaoui, A. H.; Beurroies, I.; Phalippou, J. Different kinds of structure in aerogels: relationships with the mechanical properties. J. Non-Cryst.

Solids 1998, 241, 45-52. 


\section{TABLE OF CONTENTS/ABSTRACT GRAPHIC}

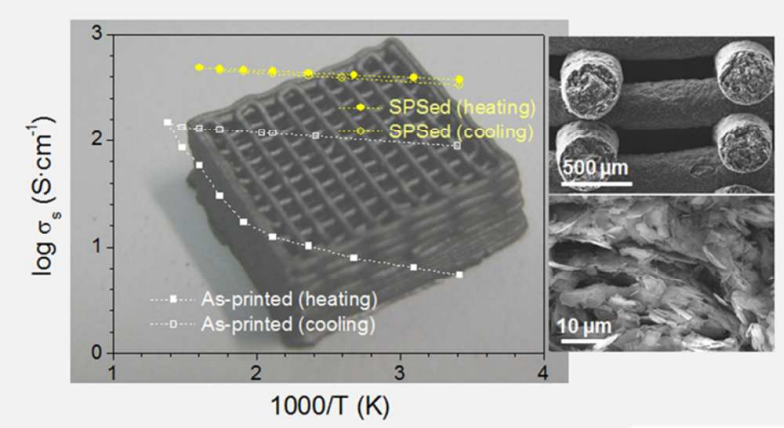

16

17

18

19

20

21

22

23

24

25

26

27

28

29

30

31

32

33

34

35

36

37

38

39

40

41

42

43

44

45

46

47

48

49

50

51

52

53

54

55

56

57

58

59

60 